\title{
Karakteristik dan Pembentukan Batuan Beku di Pegunungan Jiwo, Bayat, Jawa Tengah
}

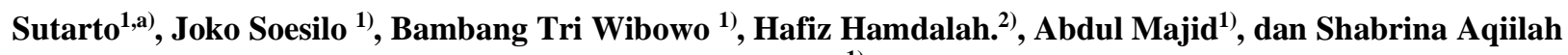 \\ Nurindra $^{1)}$ \\ 1) Jurusan Teknik Geologi Fakultas Teknologi Mineral UPN Veteran Yogyakarta \\ 2) Jurusan Teknik Geofisika Fakultas Teknologi Mineral UPN Veteran Yogyakarta \\ a) Email korespondensi: sutarto_geomin@upnyk.ac.id
}

\begin{abstract}
ABSTRAK
Pegunungan Jiwo, merupakan salah satu dari tiga wilayah di Jawa yang memperlihatkan singkapan batuan-batuan metamorf Pra-Tersier yang tidak selaras diatasnya diendapkan batuan sedimen Tersier dan diterobos oleh batuan-batuan beku seperti gabro, diabas, basalt, dan diorite. Penelitian ini bertujuan untuk mengetahui karakteristik mineralogi dan tekstur, serta hubungan pembentukan antar batuan beku. Metode yang digunakan adalah pendekatan petrografi serta pentarikhan umur dari data peneliti terdahulu. Batuan beku hasil kegiatan magmatisme tesebut di atas, hadir sebagai intrusi (stok, retas) maupun ekstrus (lava). Kenampakan mikroskopik, gabro dan gabro mikro atau diabas umumnya memperlihatkan tekstur equigranular, kumulus, ofitik, subofitik, dan diabasik disusun oleh mineral-mineral primer plagioklas $( \pm 52-66 \%)$, olivin $( \pm 0-14 \%)$, piroksen $( \pm 4-18 \%)$, mineral opak $( \pm 2-12 \%)$. Sebagian besar gabro mengalami ubahan hidrotermal lemah-sedang, dicirikan oleh terubahnya beberapa mineral primer menjadi mineral-mineral klorit, silika, epidot, karbonat, serpentin, dan aktinolit. Basalt secara mikroskopik, memperlihatkan tekstur inequigranular, porfiritik-porfiroafanitik, disusun oleh mineral-mineral primer plagioklas, olivin, piroksen, mineral opak dengan mineral sekunder seperti klorit dan karbonat. Batuan-batuan beku tersebut, diperkirakan merupakan hasil magmatisme yang

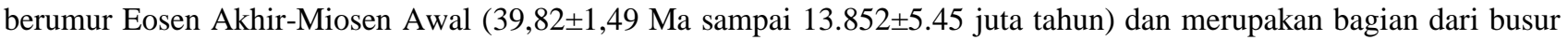
kepulauan Sunda-Banda, terbentuk karena subduksi kearah utara lempeng Hindia-Australia di bawah bagian tenggara lempeng Eurasia.
\end{abstract}

Kata Kunci: batuan beku; basalt; gabro; gabro mikro; magmatisme

\begin{abstract}
The Jiwo Hills are one of three regions in Java that show pre-Tertiary metamorphic rock outcrops that are unconformably underlain the Tertiary sedimentary rocks and intruded by igneous rocks such as gabbros, diabases, basalts, and diorites. This study was aimed to determine the mineralogy and texture characteristics, as well as the igneous rocks formation. The method used were petrographic approach and age dating from previous research data. Igneous rocks in the research area present both as intrusion (stock, dyke) and extrusion (lava). Microscopically, gabbro and micro gabbro or diabas generally shows an equigranular, cumulus, ophytic, subophytic, and diabasic textures composed of primary minerals such as plagioclases $( \pm 52-66 \%)$, olivines $( \pm 0-14 \%)$, pyroxenes ( $\pm 4-18 \%)$, and opaque minerals $( \pm 2-12 \%)$. Most of the gabbro show a weak-moderate hydrothermal alteration, characterized by the replacement of several primary minerals into secondary minerals such as chlorites, silicas, epidote, carbonates, serpentines, and actinolites. Petrographically, basalt showing inequigranular texture, porphyritic and porphyroaphanitic, composed of primary minerals plagioclases, olivines, pyroxenes, opaque minerals with secondary minerals such as chlorites and carbonates. These igneous rocks are thought to be the result of the Late Eocene-Early Miocene magmatism (39.82 \pm 1.49 to 13,852 $\pm 5.45 \mathrm{Ma})$ and are part of the Sunda-Banda Arc, due to subduction towards the north of the Indian-Australian plate under the southeastern part of the Eurasian plate.
\end{abstract}

Keywords: basalt; gabbro; igneous rocks; magmatism; micro gabbro

\section{PENDAHULUAN}

Busur kepulauan Sunda-Banda merupakan busur kepulauan terpanjang di Indonesia membentang dari Pulau Sumatra hingga Pulau Damar, menjadi salah satu busur penting yang mempunyai potensi mineralisasi dan alterasi hidrotermal (van Leeuwen, 1994; Charlile and Mitchell, 1994). Busur kepulauan ini terbentuk sebagai akibat adanya subduksi kearah utara lempeng India-Austrasia di bawah bagian tenggara lempeng Eurasia yang dikenal sebagai Sundaland (Hamilton, 1979; Katili, 1989). Segmen bagian barat busur banyak dijumpai mineralisasi epitermal Au-Ag sulfidasi rendah, sebaliknya pada segmen bagian timur banyak diketemukan mineraliasi tipe porfiri $\mathrm{Cu}$-Au yang juga berasosiasi dengan berbagai tipe endapan epitermal Au-Ag-Pb-Zn (Charlile dan Mitchell, 1994) seperti di Batu Hijau, Elang, Tumpang Pitu (Hellman, 2010; Maryono et al., 2012; Horison et al., 2018) dan Selogiri (Muthi et al., 2012, Sutarto, et al., 2016). Setijadji dan Maryono (2012) membagi busur kepulauan Sunda-Banda menjadi 3 segmen yaitu busur Sunda bagian barat 
(the Western Sunda arc) meliputi Pulau Sumatra, busur Sunda bagian timur (the Eastern Sunda arc) meliputi pulau Jawa, Bali, Lombok, Sumbawa serta kepulauan Flores, dan busur Banda meliputi kepulauan sebelah timur Flores. Busur Sunda bagian timur mempunyai tatanan tektonik dan magmatisme yang kompleks (Setijadji dan Maryono, 2012) juga mempunyai kontribusi yang penting sebagai prospek mineralisasi bijih hidrotermal.

Pegunungan Jiwo, Kecamatan Bayat terletak di bagian selatan Kabupaten Klaten, berbatasan dengan wilayah Kabupaten Gunung Kidul dan Kabupaten Sukoharjo (Gambar 1) yang banyak ditemukan intrusi dan ekstrusi batuan-batuan beku, berada pada busur Sunda bagian timur ini, walaupun sedikit terpisah dari jalur magmatik Pegunungan Selatan Jawa Timur, tetapi sangat memungkin juga mengalami proses alterasi dan mineralisasi logam tertentu, seperti halnya terjadinya mineralisasi porfiri $\mathrm{Cu}-\mathrm{Au}$ dan epitermal Au-Ag di Selogiri, Wonogiri yang terletak sekitar $25 \mathrm{~km}$ sebelah timur Bayat. Penelitian ini bertujuan untuk mengetahui karakteristik mineralogi dan tekstur, serta hubungan pembentukan antar batuan beku.

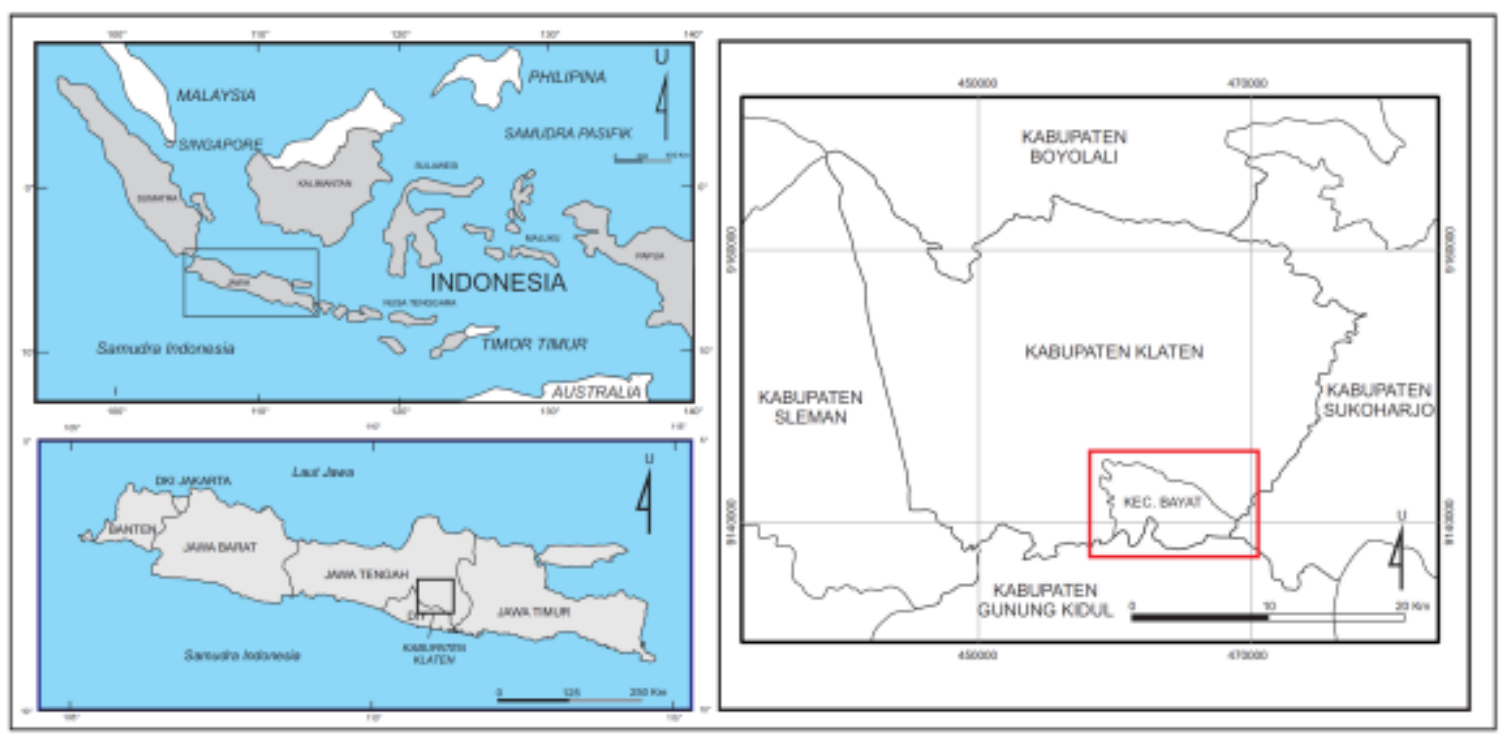

Gambar 1. Peta Lokasi daerah Pegunungan Jiwo, Bayat, Kabupaten Klaten, Jawa Tengah

\section{METODE}

Penelitian ini dilakukan dengan melakukan pemetaan geologi permukaan detil di lapangan dikombinasikan dengan datadata penelitian yang dilakukan oleh peneliti terdahulu. Perkiraan batas sebaran batuan beku disamping dengan metode lintasan dan kompas, juga menggunakan pemotretan udara dengan drone. Data-data laboratorium diantaranya adalah 30 sayatan tipis batuan beku untuk Analisa petrografi untuk mendapatkan komposisi dan tekstur detil batuan. Data umur batuan beku mengacu dari peneliti terdahulu yang menggunakan metode radiometrik K/Ar dan U-Pb SHRIMP.

\section{HASIL DAN PEMBAHASAN}

\subsection{Geologi Pegunungan Jiwo}

Stratigrafi Pegunungan Selatan dibagi menjadi dua bagian, yaitu bagian timur dan bagian barat. Stratigrafi bagian timur terutama daerah Pacitan dan sekitarnya telah disusun oleh beberapa ahli geologi, antara lain Sartono (1964), Nahrowi (1978), serta Hanang Samudra (1992). Sedangkan stratigrafi bagian barat juga telah banyak diteliti diantaranya oleh Bothe (1928)); van Bemmellen (1949), Surono et al. (1992) dan Suyoto (1992). Stratigrafi Pegunungan Selatan bagian barat meliputi wilayah Gunung Kidul dan Bantul. Sedangkan Pegunungan Jiwo yang mengandung batuan-batuan yang relative lebih tua secara fisiografi termasuk ke dalam Zona Solo (Gambar 2). Walaupun demikian secara stratigrafi Pegunungan Jiwo dan Pegunungan Selatan Bagian Barat secara stratigrafi saling terkait. Uraian stratigrafi regional di bawah ini dimulai dari Batuan Pra-tersier di Pegunungan Jiwo.

Kelompok Batuan Pra Tersier (Ktm). Batuan berumur Pra-Tersier tersingkap di Pegunungan Jiwo daerah Bayat, Klaten tersusun oleh batuan metamorfosa batusabak, sekis, genis, serpentinit dan batugamping kristalin. Batugamping mengandung Orbitulina hadir sebagai lensa-lensa (bongkah) dalam batulempung. Berdasarkan kesamaannya dengan satuan batuan yang ada di daerah Luk Ulo, Kebumen, Jawa Tengah kelompok batuan ini diperkirakan berumur Kapur 
Atas (Verbeek dan Fennema, op.cit.Bothe, 1929). Secara tidak selaras di atas batuan dasar ini terdapat satuan batuan Tersier tertua di daerah Pegunungan Selatan yang terdiri dari Formasi Wungkal dan Formasi Gamping.

Formasi Gamping-Wungkal (Tew). Formasi Wungkal dicirikan oleh Kalkarenit dengan sisipan batupasir dan batulempung, sedangkan Formasi Gamping dicirikan oleh kalkarenit dan batupasir tufaan,sedangkan di daerah Gamping (sebagai tipe lokasi), Formasi Gamping ini dicirikan oleh batugamping yang berasosiasi dengan gamping terumbu.

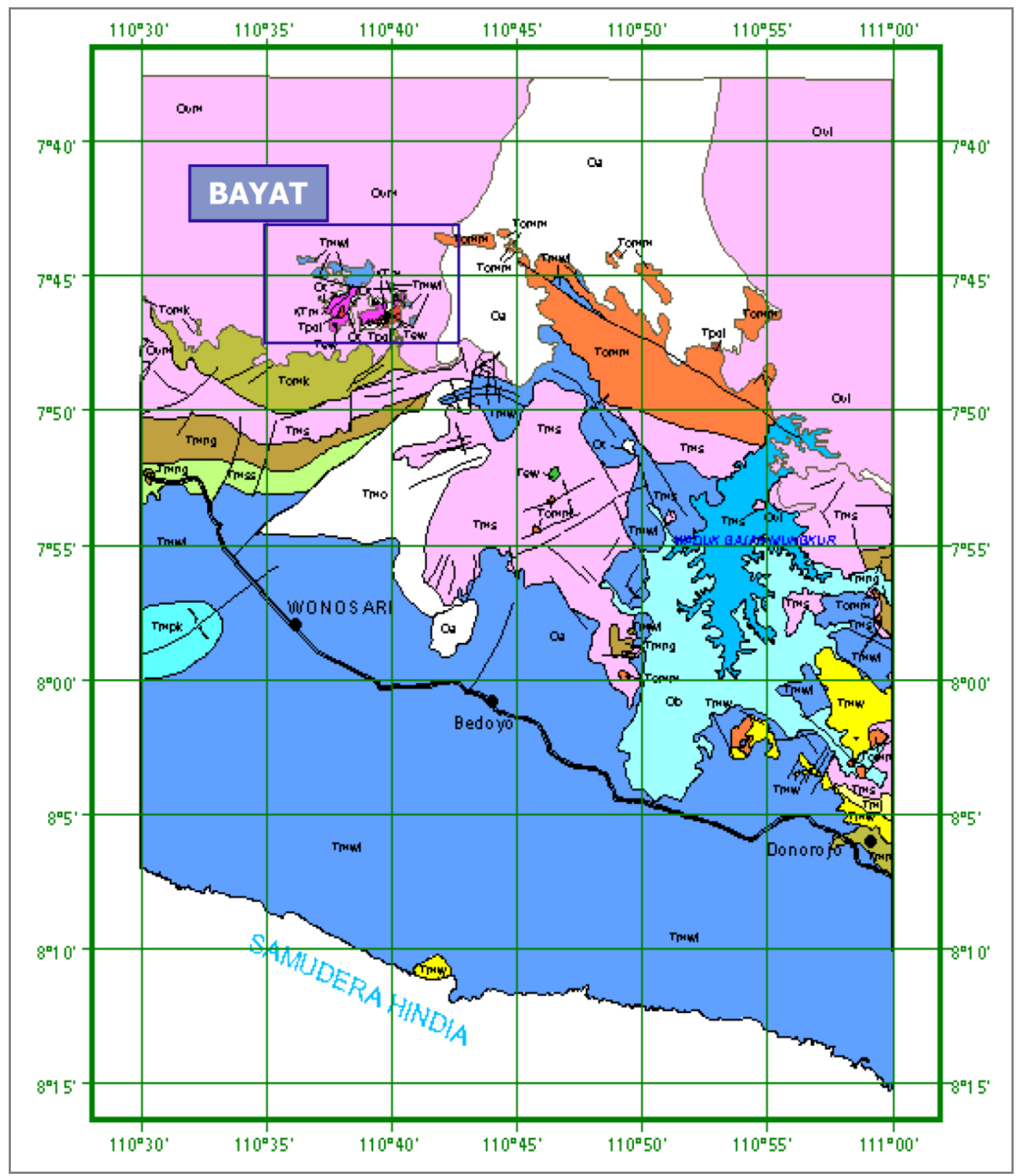

Gambar 2. Peta Geologi Regional Lembar Surakarta, daerah Bayat berada di bagian utara (kotak biru).

Hubungan antara formasi-formasi ini belum diketahui secara pasti. Beberapa peneliti menafsirkan sebagai ketidakselarasan (Sumosusastro, 1956 dan Marks, 1957) dan peneliti lainnya menafsirkan hubungan kedua Formasi tersebut selaras (Bothe, 1929, Sumarso dan Ismoyowati, 1975), sedangkan Surono et al. (1989) menyebutkan sebagai Formasi Gamping-Wungkal yang merupakan satu Formasi yang tidak terpisahkan. Namun demikian semua peneliti tersebut sepakat bahwa kedua Formasi tersebut berumur Eosen Tengah - Atas. Di atas Formasi Wungkal dan Formasi gamping ditutupi secara tidak selaras oleh sedimen volkanoklastik yang dikelompokkan sebagai Formasi Kebo, Formasi Butak, Formasi Semilir, Formasi Nglanggran dan Formasi Sambipitu.

Formasi Kebo-Butak (Tomk). Formasi Kebo terdiri dari perselingan konglomerat, batupasir tufaan, serpih dan lanau , dan dibeberapa tempat dijumpai adanya lava bantal dan intrusi diorit. Ketebalan Formasi ini sekitar 800 meter dan diendapkan di dalam lingkungan laut, pada umumnya memperlihatkan endapan aliran gravitasi (gravity-flow deposits). 
Lokasi tipe Formasi Butak terdapat di gunung Butak yang terletak di Sub Zona Baturagung, tersusun oleh litologi breksi, batupasir tufaan, konglomerat batuapung, batulempung dan serpih yang memperlihatkan perselingan dan menunjukkan ciri endapan aliran gravitasi di lingkungan laut yang berumur Oligosen. Ciri Formasi Kebo dan Formasi Butak di beberapa tempat tidak begitu nyata sehingga pada umumnya beberapa peneliti menyebutkan sebagai Formasi Kebo Butak yang berumur Oligosen Atas.

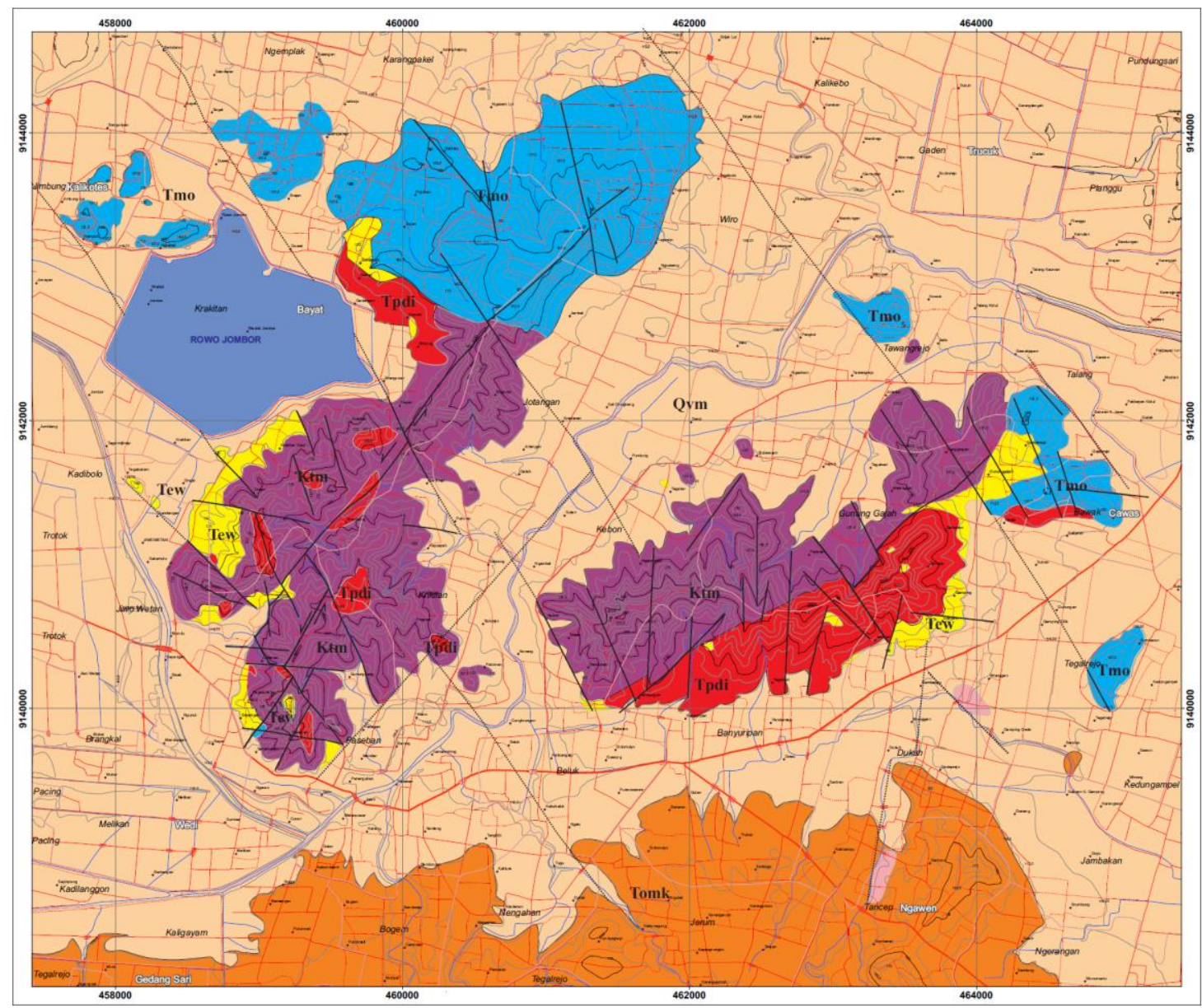

Gambar 3. Peta Geologi Pegunungan Jiwo, Bayat (Kompilasi dan modifikasi dari Surono dkk., 1999; Jatmiko Setiawan, 2000)

Formasi Oyo (Tmo) dan Formasi Sambipitu. Selaras diatas formasi Semilir - Nglanggran. Lokasi tipenya di Sambipitu. Terdiri dari perselingan dari batu pasir berwarna coklat kehijauan dengan serpih hijau dan batulanau. Sering dijumpai adanya klastika lempung didalam batupasir. Formasi ini juga diendapkan turbidit di lingkungan laut dalam. Berumur Miosen Awal bagian atas $\left(\mathrm{N}_{8}-\mathrm{N}_{9}\right)$. Tidak selaras di atas Formasi Sambipitu. Lokasi typenya adalah di kali Oyo. Terdiri dari batugamping fragmental atau batugamping konglomeratan, batugamping pasiran kalkarenit, batupasir tufaan dan napal. Struktur sedimen yang biasanya dijumpai adalah lapisan perselang-selingan antara kalkarenit dan napal. Diendapkan dalam lingkungan laut dangkal (20 - 100 mete), atau Neritik tepi sampai Neritik Tengah, di bawah pengaruh agitasi ombak yang agak tenang. Formasi ini berumur Miosen Tengah.

\subsection{Magmatisme}

Soeria-atmadja et al. (1994) membagi magmatisme Tersier di Jawa menjadi dua periode, yaitu periode magmatisme Eosen Akhir-Miosen Awal dan periode Miosen Akhir-Pliosen. Batuan batuan-batuan beku vulkanik dan vulkaniklastik tersebar di sepanjang bagian selatan pulau Jawa umumnya berafinitas toleitik, sedangkan magmatisme Miosen AkhirPliosen yang mempunyai spectrum magma toleitik, kalk-alkali hingga kalk-alkali $\mathrm{K}$ tinggi tersebar di sebelah utara bagian pulau, dan sebagian terletak pada posisi yang sama dengan produk magmatisme Eosen Akhir-Miosen Awal (Gambar 4). Batuan-batuan vulkanik Miosen Akhir-Pliosen sangat banyak ditemukan di wilayah Jawa Tengah dan Jawa Barat, sedangkan di wilayah Jawa Timur batuan vulkanik Mio-pliosen di bagian utara banyak tertutup oleh endapan vulkanik Kuarter (Gafoer dan Samodra, 1993; Ratman et al., 1998). 


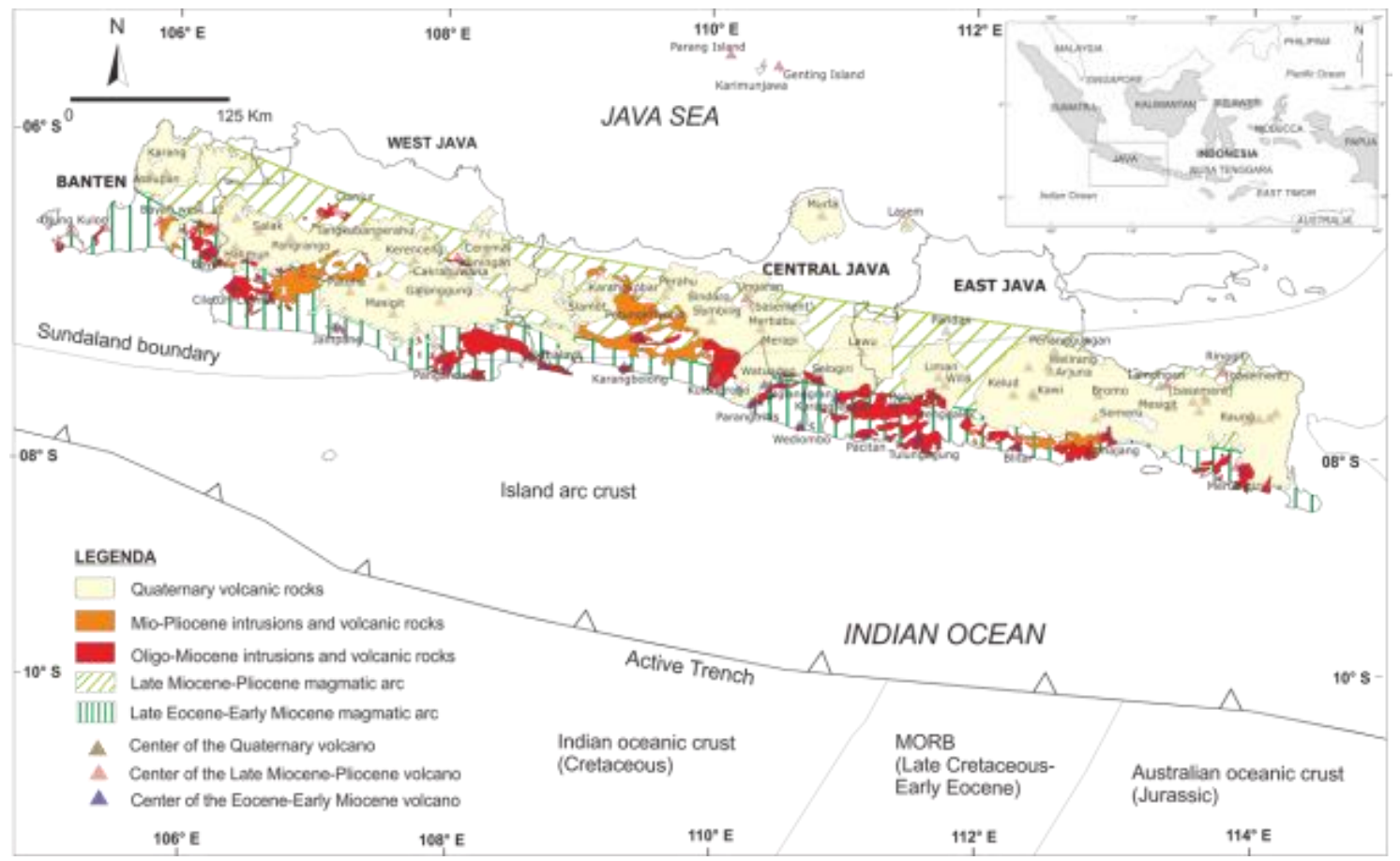

Gambar 4. Distribusi busur magmatik Tersier, Batuan-batuan vulkanik Tersier, pusat gunungapi Kenozoikum serta tipe kerak batuan dasar di pulau Jawa (Sutarto et al., 2016).

Batuan beku tertua pada busur magmatik Eosen Akhir-Miosen Awal adalah lava andesit toleitik dari Formasi Besole ditemukan di daerah Pacitan. Dengan metode pentarihan K-Ar, batuan tersebut menunjukkan umur $42.73 \pm 9.87$ juta tahun (Soeria-atmadja et al., 1994), sedangkan yang termuda juga berupa lava andesit di Pacitan menunjukkan umur $15.03 \pm 0.88$ juta tahun (JICA-JOGMEC, 2004 dalam Setijadji et al., 2006). Batuan vulkanik pada magmatisme Miosen Akhir-Pliosen diwakili lava basalt di Bayah yang menunjukkan umur 13.7 \pm 1.8 juta tahun (Soeria-atmadja et al., 1994; Sutanto et al., 1994) dan batuan basalt di pilau Genting, Karimunjawa dengan kisaran umur anatar $2.5 \pm 0.1$ hingga $1.8 \pm 0.3$ juta tahun (Soeria-atmadja et al., 1985).

Beberapa retas basaltik (Winong, Brumbung, Bukit Merak, Pager Jurang, dll) dan stok gabroik (Desa Bendungan, Bukit Pendul, Bukit Kebo) menunjukkan umur 31 - 40 juta tahun. (Tabel 1) menerobos formasi-formasi tersebut di atas. Kandungan titan (Ti) dan miobium (Nb) yang rendah dari gabro dan basalt tersebut menunjukan batuan beku orogenik.. Di Bukit Temas dan Desa Bendungan formasi batuan berumur Eosen ini tertutup secara tidak selaras (nonconformity) oleh batugamping terumbu Formasi Wonosari (Gambar 3).

Satuan batuan ini terdiri dari gabro, gabromikro atau diabas, dan basalt serta dioritmikro. Beberapa batuan tersebut hadir sebagai stok maupun dike yang tersingkap di Jiwo Barat maupun Jiwo Timur; basalt umumnya sebagai dike dengan ketebalan beberapa meter yang pada umumnya memotong filit atau sekis. Di Dusun Brumbung (Jiwo Barat) kontak basalt dengan filit memberikan efek bakar dan meskipun lapuk tetapi dapat diamati dengan baik, sementara singkapan yang lain dijumpai di Gunung Sari, Kali Kebo, Gunung Merak dan Gunung Cakaran. Sedangkan gabro merupakan dike yang mempunyai ketebalan lebih dari 25 meter seperti halnya yang terdapat di Dusun Bendungan, Gunung Pendul dan lereng selatan Gunung Temas.

Penanggalan radiometrik dengan metode isotopik Potasium-Argon menunjukkan bahwa gabro dan basalt di perbukitan

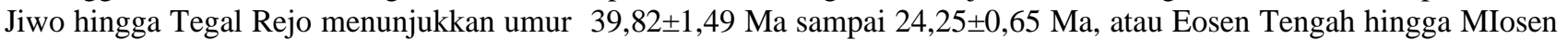
Awal awal (Sutanto, et al, 1994; Soeria-Atmadja dkk, 1994; Smith, 2005; Surono dkk., 2006). Sedangkan pada batuan

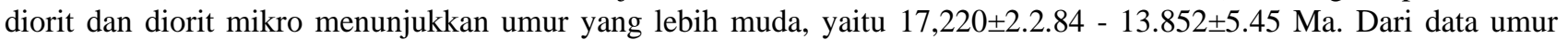
batuan beku tersebut di atas menunjukkan minimal terdapat dua episode magmatisme yang mengasilkan batuan beku di Pegungungan Jiwo, walupun masih dalam kisaran magmatisme Eosen Akhir-Miosen Awal. Semua batuan yang berkomposisi basaltik berafinitas calk-alkali yang genesanya berhubungan dengan penunjaman kerak samodra. 
Tabel 1. Umur radiometrik K/Ar dan U-Pb SHRIMP dari beberapa contoh batuan Daerah Perbukitan Jiwo dan Desa Tegalrejo

\begin{tabular}{|c|c|c|c|}
\hline BATUAN & LOKASI & UMUR & REFERENSI \\
\hline 2004pk05, Diorit & Sutojayan & $\begin{array}{l}13.852 \pm 5.45 \quad \text { (Miosen } \\
\text { Tengah). Metode K-Ar }\end{array}$ & Surono dkk., 2006. \\
\hline $\begin{array}{l}\text { 2004PK01, Diorit } \\
\text { Mikro }\end{array}$ & Penggingan Bayat & $\begin{array}{l}\text { 17,220 } \pm 2.2 .84 \quad \text { jtl } \\
\text { (Miosen Awal-Tengah). } \\
\text { Metode K-Ar }\end{array}$ & Surono dkk., 2006. \\
\hline BY52, Basalt & Tegalrejo & $\begin{array}{l}24,25 \pm 0,65 \quad(\text { Miosen } \\
\text { Awal). Metode K-Ar }\end{array}$ & Soeria-Atmadja dkk, 1994. \\
\hline $\begin{array}{l}\text { Lava Bantal } \\
\text { Anggota Santren }\end{array}$ & Desa Santren & $\begin{array}{l}24,7 \pm 1,0 \text { (Miosen Awal). } \\
\text { Metode U-Pb SHRIMP }\end{array}$ & Smith, 2005 \\
\hline 2004PK02,Diabas & G. Bokol, Cermo & $\begin{array}{l}30,04 \pm 4.62 \quad \text { Oligosen } \\
\text { Awal). Metode K-Ar }\end{array}$ & Surono dkk., 2006. \\
\hline $\begin{array}{l}\text { BY47, } \\
\text { Diabas/basalt }\end{array}$ & Winong, Bayat & $\begin{array}{l}31,25 \pm 0,90 \quad \text { Oligosen } \\
\text { Awal). Metode K-Ar. }\end{array}$ & $\begin{array}{l}\text { Sutanto, dkk., (1994), } \\
\text { Soeria-Atmadja dkk, } 1994 .\end{array}$ \\
\hline $\begin{array}{l}2004 \text { PK07, Gabro } \\
\text { Mikro }\end{array}$ & G. Pendul. & $\begin{array}{l}32,852 \pm 6,57 \text { (Oligosen } \\
\text { Awal). Metode K-Ar. }\end{array}$ & Surono dkk., 2006. \\
\hline BY48, Basalt & Bumbung, Bayat & $\begin{array}{l}33,15 \pm 1,00 \quad \text { (Oligosen } \\
\text { Awal). Metode K-Ar. }\end{array}$ & $\begin{array}{l}\text { Sutanto, dkk., (1994), } \\
\text { Soeria-Atmadja dkk, } 1994 .\end{array}$ \\
\hline BY50, Diabas & Pagerjurang, Bayat & $\begin{array}{l}39,82 \pm 1,49 \quad(\text { Eosen } \\
\text { Tengah). Metode K-Ar. }\end{array}$ & $\begin{array}{l}\text { Sutanto, dkk., (1994), } \\
\text { Soeria-Atmadja dkk, } 1994 .\end{array}$ \\
\hline
\end{tabular}

\subsection{Karakteristik Batuan Beku}

Batuan-batuan beku hasil kegiatan magmatisme tesebut di atas, hadir sebagai batuan beku plutonik (gabro, gabro mikro atau diabas, diorit), dan batuan beku vulkanik (basalt), yang hadir baik sebagai intrusi (retas) maupun lava. Sebagian besar batuan beku tersebut di permukaan dalam keadan lapuk, dan hanya sebagian kecil singkapan yang memperlihatkan keadaan yang fres atau segar, diantaranya pada beberapa inti batuan beku yang mengalami pelapukan mengulit bawang (spheroidal weathering). Secara umum komposisi mineralogi batuan-batuan tersebut di atas, retatif sama, umumnya mengandung plagioklas, olivine, piroksen, mineral opak mengalami ubahan hidrotermal lemah-sedang. Gabro, gabro mikro atau sering disebut diabas, dan basalt dibedakan dari ukuran butirnya (berdasarkan klasiifikasi Streckeisen, 1976), dimana gabro disusun kristal yang sebagian besar berukuran $>3 \mathrm{~mm}$, gabro mikro atau diabas berukuran 1-3, sedangkan basalt berukun kristal sebagian besar $<1 \mathrm{~mm}$. Karena sebagian besar wilayah Pegunungan Jiwo tertutup oleh vegetasi yang lebat dan karena banyaknya pemukiman, maka sulit mendapatkan batas dari beberapa tipe batuan beku di atas.

Gabro pada kenampakan lapangan umumnya lapuk berwarna kecoklatan, sedangkan pada bagian yang fres memperlihatkan warna abu-abu gelap kehijauan. Di daerah Sutojayan memperlihatkan kenampakan layer tekstur cumulus, ukuran butir sebagian besar $>3 \mathrm{~mm}$. Ukuran Kristal gabro yang paling kasar terdapat di lereng G. Jabalkat. Perbandingan komposisi mineral dapat dilihat pada Tabel 2. Pada kenampakan mikroskopik, umumnya memperlihatkan tekstur equigranular, cumulus, ofitik dan subofitik, disusun oleh mineral-mineral primer plagioklas $( \pm 58-60 \%)$, Olivin $( \pm 3-14 \%)$, piroksen $( \pm 4-14 \%)$, mineral opak, baik kemungkinan primer maupun sekunder $( \pm 2-12 \%)$. Sebagian besar gabro mengalami ubahan hidrotermal lemah-sedang, yang dicirikan oleh terubahnya beberapa mineral primer menjadi mineral-mineral klorit $( \pm 5-18 \%)$, silica $( \pm 0-3 \%)$, epidot $( \pm 2 \%)$, karbonat $( \pm 2-4 \%)$, serpentin $( \pm 4 \%)$, aktinolit $( \pm 4 \%)$. Contoh batuan dapat dilihat pada Gambar 5. 
24 ISSN 2549-7197 (cetak), ISSN 2549-564X (online)

JMEL, Volume 4 Nomor 2, 2020
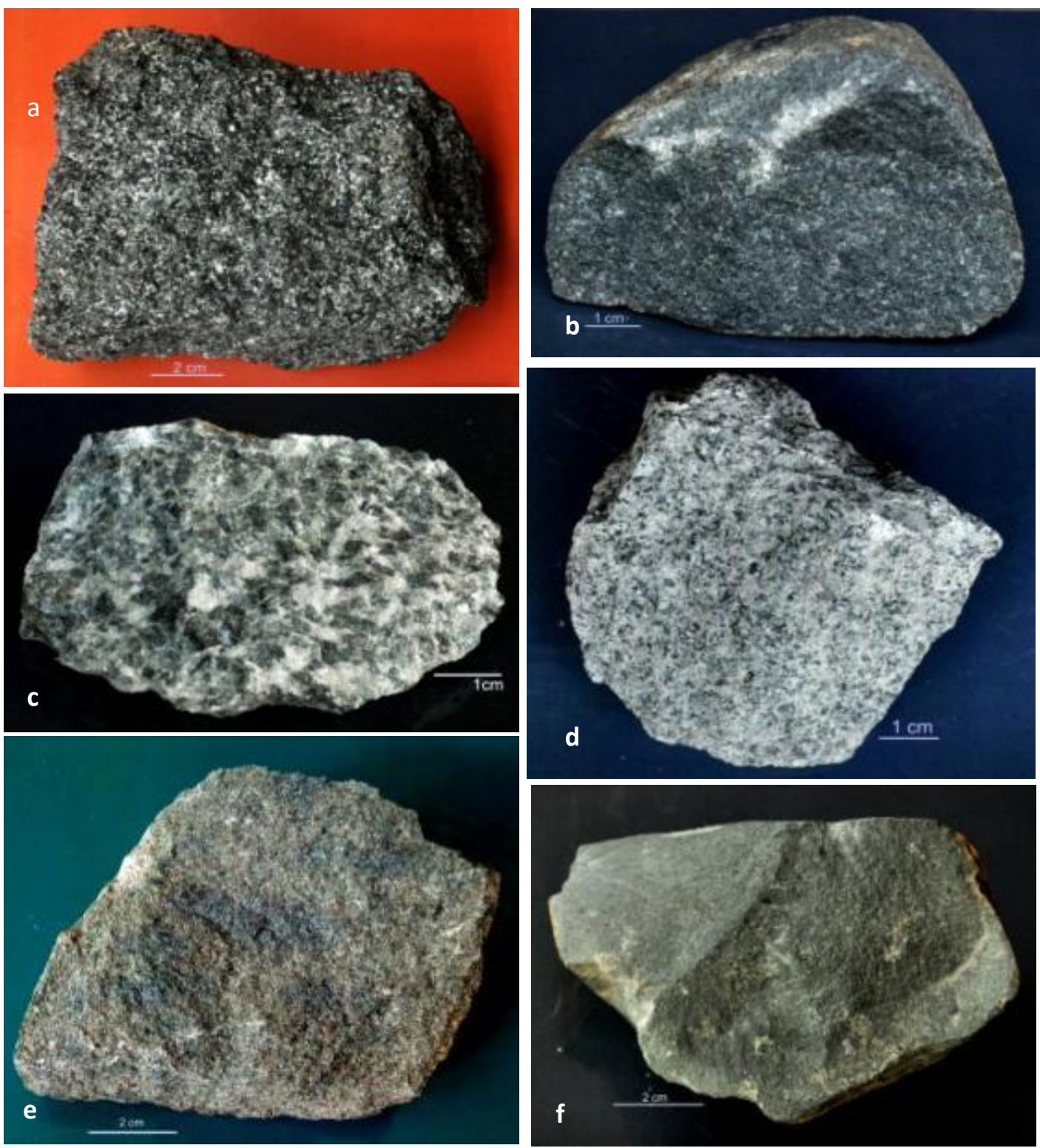

Gambar 5. Beberapa kenampakan contoh batuan beku intrusi di perbukian Jiwo Barat dan Jiwo Timur. a) Gabro di daerah Sutojayan, b). Gabromikro, daerah Sutojayan, c) Gabro terubah kuat, gunung Jabalkat, d) Diorit piroksen, e). Gabromikro (diabas) gunung Temas, dan f). Basalt di lereng gunung Jabalkat.

Gabro mikro atau diabas, seperti halnya gabro, juga di lapangan pada umumnya terlihat lapuk, sedangkan dalam keadaan segar beberapa terlihat berwarna sedikit kecoklatan. Dibedakan dengan gabro, yang utama karena ukuran kristalnya 1-3 mm dan kenampakan tekstur diabasik pada beberapa conto. Pada kenampakan mikroskopis memperlihatkan kenampakan tekstur equi granular, ofitik, dibasik. Pada kenampakan mikroskopik, umumnya memperlihatkan tekstur equigranular, cumulus, ofitik dan subofitik, disusun oleh mineral-mineral primer plagioklas $( \pm 52-66 \%)$, Olivin $( \pm 0$ $10 \%)$, piroksen $( \pm 4-18 \%)$, mineral opak, baik kemungkinan primer maupun sekunder $( \pm 4-5 \%)$. Sebagian besar gabro mengalami ubahan hidrotermal lemah, yang dicirikan oleh termahnya beberapa mineral primer nenjadi mineral-mineral klorit $( \pm 4-16 \%)$, silica $( \pm 0-7 \%)$, karbonat $( \pm 2-12 \%)$. 
Tabel 2. Komposisi Batuan beku di Sutojayan, Jabalkat, Cakaran, dan Temas, Pegunungan Jiwo, Bayat

\begin{tabular}{|c|c|c|c|c|c|c|c|}
\hline \multirow[b]{2}{*}{ KODE SAMPEL } & \multicolumn{2}{|c|}{ Sutojayan } & \multicolumn{2}{|c|}{ Jabalkat } & \multirow{2}{*}{$\begin{array}{l}\text { Cak } \\
\text { BY36b }\end{array}$} & \multirow{2}{*}{$\frac{\mathbf{G g}}{\mathrm{BB} 4}$} & \multirow{2}{*}{$\begin{array}{l}\text { Temas } \\
\text { BB5 }\end{array}$} \\
\hline & BB1 & STN6 & BB2 & STN5 & & & \\
\hline BATUAN & $\mathrm{G}$ & GM/D & $\mathrm{G}$ & $\mathrm{G}$ & GM/Di & $\mathrm{G}$ & $\mathrm{G}$ \\
\hline Plagioklas & 60 & 58 & 58 & 60 & 56 & 60 & 58 \\
\hline Olivin & 14 & & & 12 & 8 & 13 & \\
\hline Piroksen & 4 & 14 & 11 & 13 & 13 & 7 & 14 \\
\hline Mineral Opak & 3 & 5 & 2 & 2 & 5 & 3 & 2 \\
\hline \multicolumn{8}{|l|}{ Gelas Volk } \\
\hline $\begin{array}{l}\text { MINERAL } \\
\text { SEKUNDER }\end{array}$ & 19 & 23 & 29 & 8 & 16 & 17 & 24 \\
\hline Klorit & 15 & 4 & 16 & 5 & 4 & 15 & 18 \\
\hline Kuarsa & & 7 & 3 & & & & \\
\hline Epidot & & & 2 & & & & \\
\hline Karbonat & & & 4 & 3 & 12 & 2 & \\
\hline Mineral Lempung & & 12 & & & & & \\
\hline Serpentin & 4 & & & & & & 3 \\
\hline Tremolit & & & & & & & 5 \\
\hline Mineral Opak & & & 4 & & & & \\
\hline
\end{tabular}

Basalt umumnya membentuk dike atau sill serta lava, dalam keadaan masih fresh terlihat berwarna lebih gelap disbanding dengan gabro maupun gabro mikro. Dike/sill basalt banyak ditemukan di wilayah G. Jabalkat dan G. Cakaran, sedangkan di G. Pendul bagian timur basalt hadir sebagai lava yang memperlihatkan struktur bantal. Kenampakan mikroskopik, memperlihatkan tekstur inequigranular, porfiritik-porfiroafanitik, disusun oleh mineralmineral primer plagioklas $( \pm 56-72 \%)$, Olivin $( \pm 3-5 \%)$, piroksen $( \pm 12-14 \%)$, mineral opak, baik kemungkinan primer maupun sekunder $( \pm 4-12 \%)$. Sampel dike memperlihatkan adanya ubahan hidrotermal lemah, yang dicirikan oleh terubahnya beberapa mineral primer nenjadi mineral-mineral klorit $( \pm 0-12 \%)$ dan karbonat $( \pm 0-3 \%)$.

Seperti telah disampaikan di atas, bahwa magmatisme yang membentuk batuan beku di Pegunungan Jiwo juga dibarengi terjadinya alterasi dan mineralisasi di wilayah tersebut. Komposisi mineral batuan beku di Pegunungan Jiwo dapat dilihat pada Tabel 3. Bukti terjadinya alterasi hidrotermal, dapat dilihat pada beberapa kenampakan baik di lapangan maupun kenampakan mikroskopik. Pada tubuh batuan beku, juga banyak dijumpai mineral-mineral ubahan hidrotermal seperti terbentuknya mineral-mineral klorit $( \pm 4-18 \%)$, silica $( \pm 0-3 \%)$, epidot $( \pm 2 \%)$, karbonat $( \pm 2-12 \%)$, serpentin $( \pm 4 \%)$, aktinolit $( \pm 4 \%)$, dan juga diseminasi mineral-mineral pirit dan galena pada tubuh batuan beku. Kenmpakan batuan beku dapat dilihat pada Gambar 6. Foto mikroskopis kenampakan beberapa batuan di Pegunungan Jiwo yang mengalami ubahan hidrotermal dapat dilihat pada Gambar 8. Di lereng timur Jabalkat, pada kontak sesar antara marmer dengan batulanau Formasi Wungkal, didapatkan adanya alterasi dan mineralisasi skarn. Keterdapatan endapan skan dicirikan oleh keberadaan himpunan mineral wolastonit-hedenbergit-garnet. Contoh gambar dapat dilihat pada Gambar 7. 
26 ISSN 2549-7197 (cetak), ISSN 2549-564X (online)

JMEL, Volume 4 Nomor 2, 2020

Tabel 3. Komposisi Batuan beku di Pendul dan Santren, Pegunungan Jiwo, Bayat

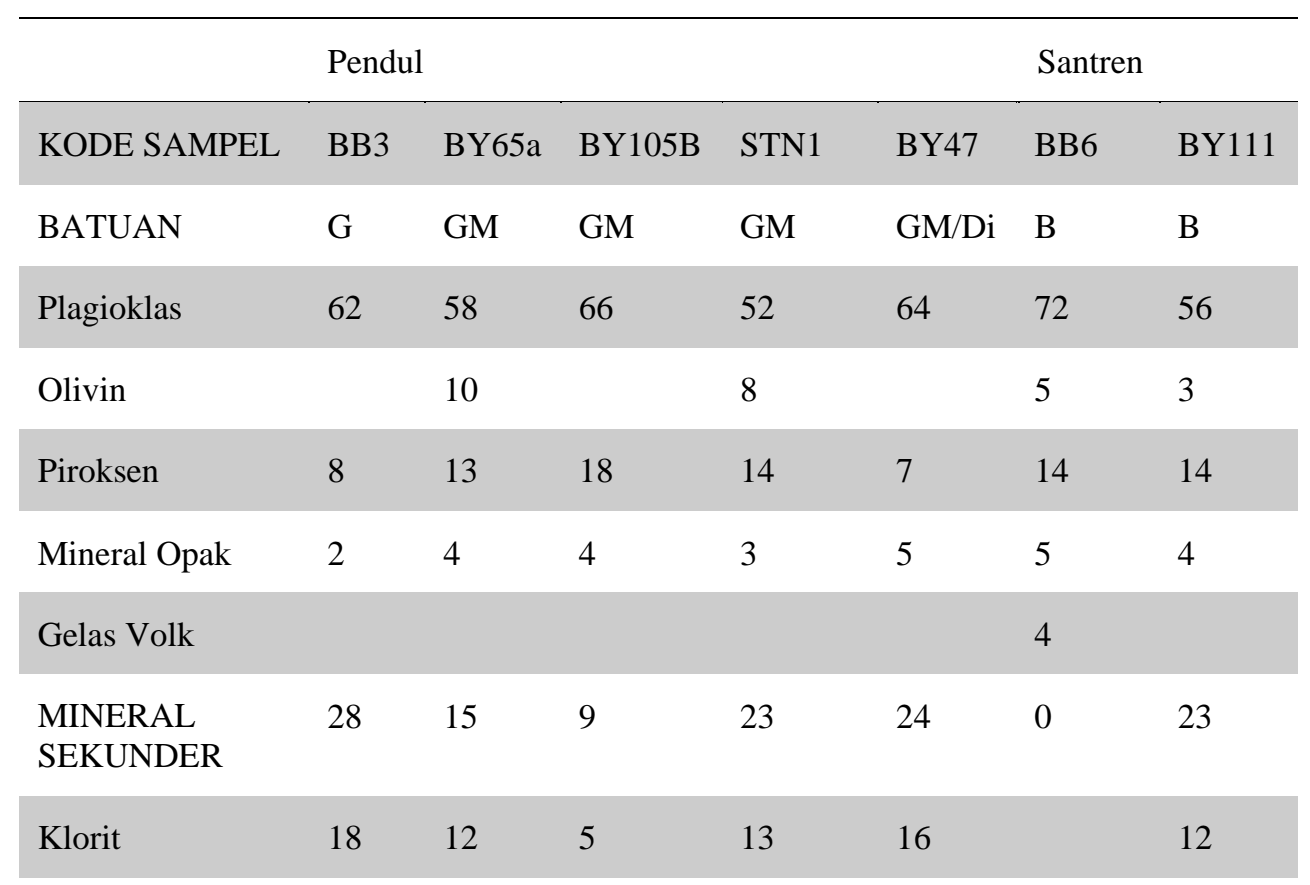

Kuarsa

Epidot

Karbonat

3

3

\begin{tabular}{lllll} 
Mineral Lempung & & 10 & 8 & \\
Serpentin & & & & \\
Tremolit & & & & 8 \\
\hline Mineral Opak & 10 & 4 & & \\
\hline
\end{tabular}



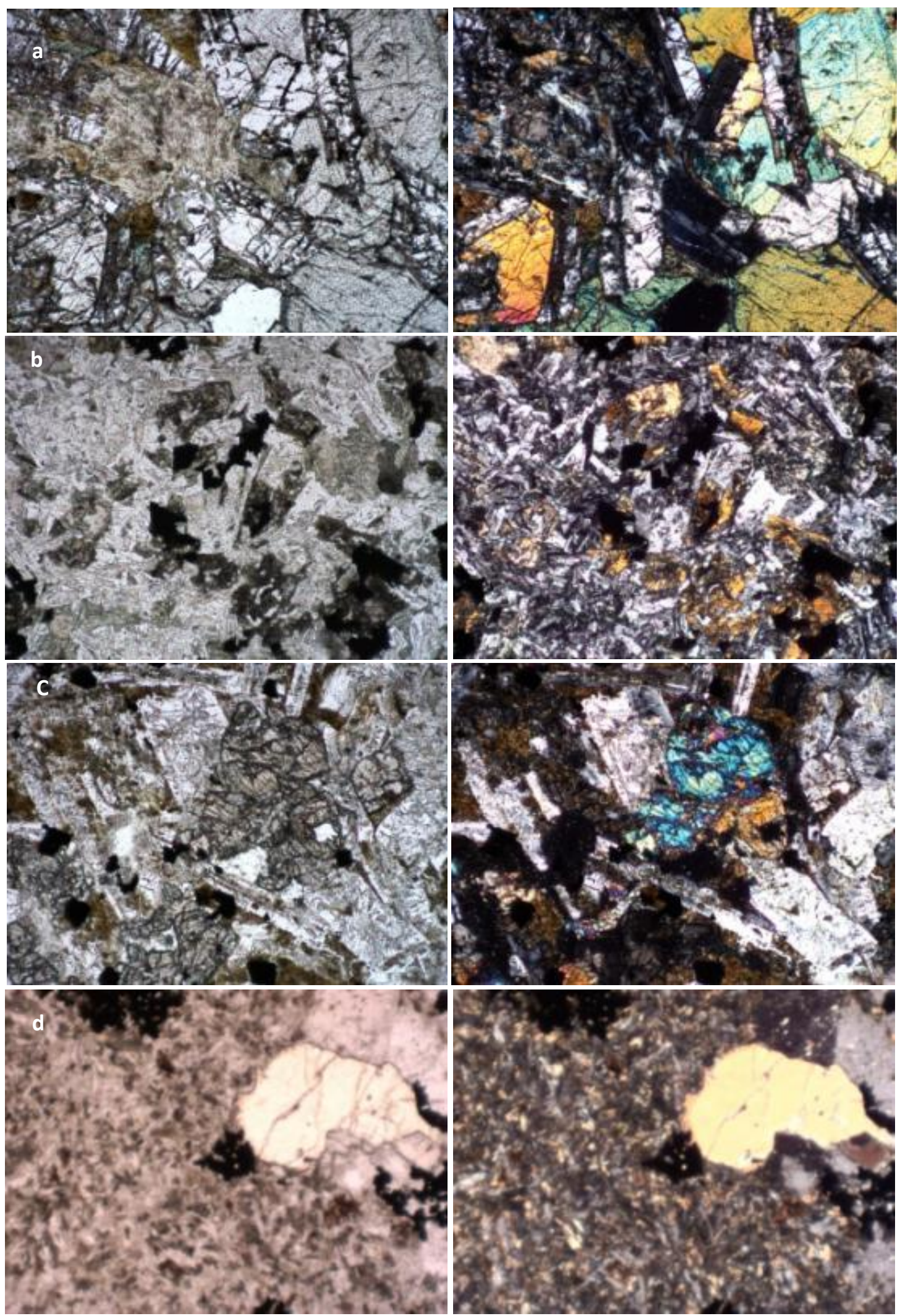

Gambar 6. Beberapa kenampakan fotomikroskopik batuan beku intrusi di perbukian Jiwo Barat dan Jiwo Timur. a)

Foto fotomikroskopik gabro daerah Sutojayan, b) Foto kenampakan fotomikroskopik Gabromikro bukit Pendul, c) Foto mikroskopik Gabro gunung Jabalkat, dan d). Fotomikroskopik basalt olivine di lereng barat gunung Jabalkat. Foto kiri mikroskopik dalam keadaan parallel nikol (PPL), sedangkan foto kanan dalam keadaan nikol silang (XPL). 
28 ISSN 2549-7197 (cetak), ISSN 2549-564X (online)

JMEL, Volume 4 Nomor 2, 2020
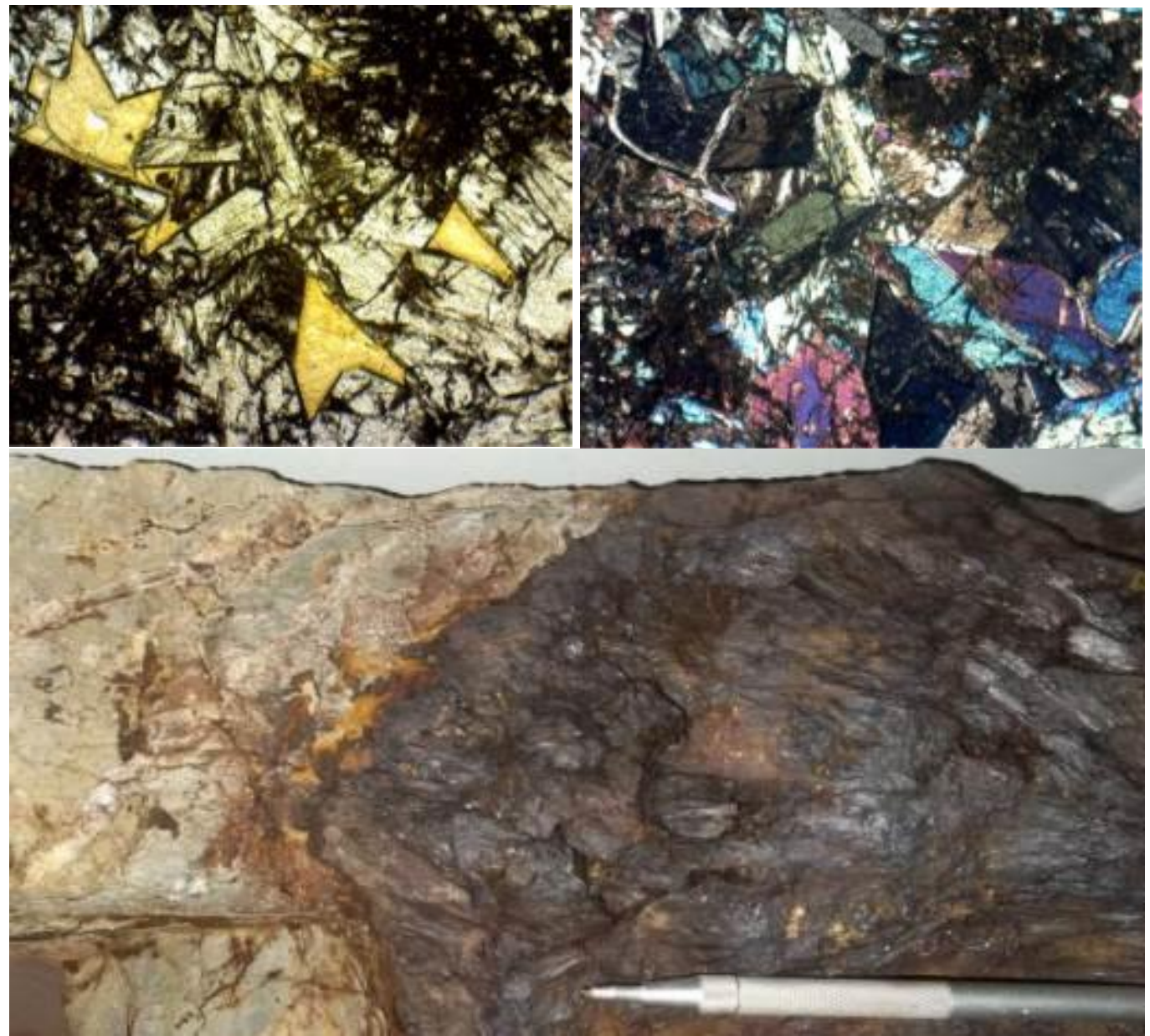

Gambar 7. Foto setangan kontak antara marmer dengan skarn wolastonit-hedenbergit, dan foto mikroskopik. Conto foto adalah singkapan batu skan yang tersusun oleh mineral garnet dan wolastonit di lereng Gunung Jabalkat, Bayat. 

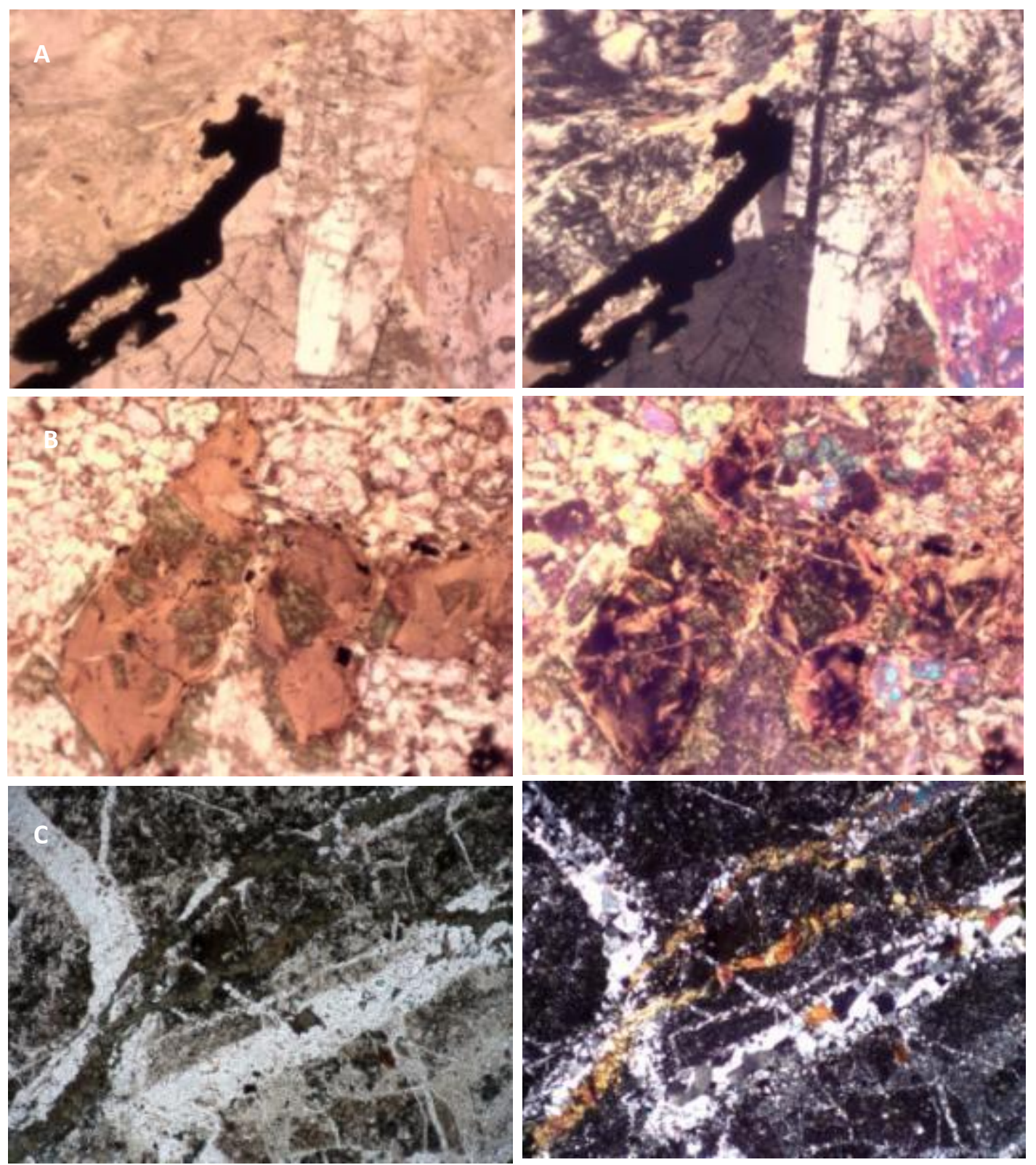

Gambar 8. Foto mikroskopis kenampakan beberapa batuan di Pegunungan Jiwo yang mengalami ubahan hidrotermal. A) Atas, Mineral opak dan klorit yang mengganti tubuh mineral plagioklas dan mineral mafik (Lokasi Sutojayan). B) Tengah, mineral klorit yang mengganti sebagian dan memotong tubuh mineral olivine, C) Bawah, urat-urat kuarsa dan klorit yang memotong batulanau di sekitra batuan beku, di lereng G. Jabalkat.

\section{KESIMPULAN}

Di Perbukitan Jiwo, banyak ditemukan berbagai batuan beku plutonik (gabro, gabro mikro atau diabas, diorit), dan batuan beku vulkanik (basalt), yang hadir baik sebagai intrusi (retas) maupun lava. Sebagian besar batuan beku tersebut di permukaan dalam keadan lapuk, dan hanya sebagian kecil singkapan yang memperlihatkan keadaan yang fres atau segar, diantaranya pada beberapa inti batuan beku yang mengalamai pelapukan mengulit bawang (spheroidal weathering);

Sebagian besar batuan beku telah mengalami ubahan hidrotermal lemah-sedang, dicirikan dengan hadirnya mineralmineral sekunder sperti klorit, silika, karbonat, mineral opak, mineral lempung, serpentin, aktinolit yang mengganti sebagian mineral-mineral primer seperti plagioklas, olivin, dan piroksen; 
Batuan-batuan beku di Perbukitan Jiwo merupakan bagian dari jalur magmatisme Eosen Akhir-Miosen Awal di Jawa, yang merupakan hasil dari proses penunjaman ke-utara lempeng Hindia-Australia di bawah bagian tenggara lempeng Eurasia yang dikenal sebagai Sundaland.

\section{UCAPAN TERIMAKASIH}

Artikel ini merupakan bagian dari Penelitian Terapan Hibah Internal yang diberikan oleh LPPM UPN "Veteran" Yogyakarta. Oleh karena itu dalam kesempatan ini, kami tim peneliti mengucapkan terimakasih kepada LPPM UPN "Veteran" Yogyakarta, yang telah memberikan hibah untuk penelitian ini. Kami ucapkan juga terimakasih kepada saudara Ilham, Kenny Latupensina, dan Aditya yang telah membantu pengambilan sampel lapangan.

\section{DAFTAR PUSTAKA}

AChD, B. (1929). Jiwo Hills and Southern Range Excursion Guide. In 4th Pacific Science Congress, Java, Bandung.

Bronto, S. (2010). Identifikasi Gunung Api Purba Pendul Di Perbukitan Jiwo, Kecamatan Bayat, Kabupaten KlatenJawa Tengah. Jurnal Geologi dan Sumberdaya Mineral, 20(1), 3-13.

Carlile, J. C., \& Mitchell, A. H. G. (1994). Magmatic arcs and associated gold and copper mineralization in Indonesia. Journal of Geochemical Exploration, 50(1-3), 91-142.

Hamilton, W., 1979, Tectonic of Indonesia Region, Geol Survey Prof. Paper 1078, U.S. Gov. Printing Office, Washington, p. 345.

Jatmiko Setiawan, 2000, Kompleks Batuan Pra-Tersier, Mula Jadi dan Implikasi Tektonik, Daerah Perbukitan JiwoBayat- Jawa Tengah (Tesis Magister). Insitut Teknologi Bandung, Bandung.

Katili, J. A., 1989. Evolution of The Southeast Asian Arc Complex, Geol. Indon. Jakarta, 12: 113-143.

Nahrowi, T.Y., Suratman, Namida, S. and Hidayat, S., 1978. Geologi Pegunungan Selatan Jawa Timur, Bagian Eksplorasi Pusat Pengembangan Teknologi Minyak dan Gas Bumi, Cepu, p. 31

Samodra, H., 1990. Tatanan Stratigrafi dan Tektonik Pegunungan Selatan Jawa Timur, Antara Pacitan dan Ponorogo. Bidang Pemetaan Geologi, Pusat Penelitian dan Pengembangan Geologi, p. 39

Sartono, S., 1964. Stratigraphy and Sedimentation of the Eastern Most Part of Gunung Sewu (East Java). Publikasi Teknik-Seri Geologi Umum No. 1 Direktorat Geologi Bandung, p. 95

Setiawan, N. I., Osanai, Y., \& Prasetyadi, C. (2013). A preliminary view and importance of metamorphic geology from Jiwo Hills in Central Java. In Prosiding Seminar Nasional Kebumian Ke-6, Teknik Geologi Universitas Gadjah Mada, pp. 12-24.

Setiawati, Y.D., Novian, M.I., Barianto, D.H. 2013. Studi Fasies Formasi Wungkal-Gamping Jalur Gunung Gajah, Desa Gunung Gajah, Kecamatan Bayat, Kabupaten Klaten, Provinsi Jawa Tengah. Prosiding Seminar Nasional Kebumian Ke-6 Teknik Geologi Universitas Gadjah Mada, pp.71-81.

Smyth, H. R., Hall, R., \& Nichols, G. J. (2008). Cenozoic volcanic arc history of East Java, Indonesia: The Stratigraphic Record of Eruptions on an Active Continental Margin. Special Papers-Geological Society of America, 436, 199.

Soeria Atmadja, R., Maury, R.C., Bellon, H., Pringgoprawiro, H., Polve, and Priadi, B., 1991, The Teriary magmatic belt in Java, Procceding of the Silver Jubbiles Symposium On the Dynamic of Subduction and Its Product, Yogyakarta, pp 98-121.

Soeria-Atmadja, R., Maury, R. C., Bellon, H., Pringgoprawiro, H., Polve, M., \& Priadi, B. (1994). Tertiary magmatic belts in Java. Journal of southeast asian earth sciences, 9(1-2), 13-27.

Soesilo, J., Sutanto dan Subandrio, A., 2000, Tatanama batuan kristalin di Jiwo Barat sesuai Sandi Stratigrafi Indonesia. Prosiding Jambore Ilmiah 20 tahun Fakultas Teknologi Mineral Universitas Trisakti, pp. 265-269.

Sutanto, S. A., Maury, R. C., \& Bellon, H. (1994). Geochronology of Tertiary Volcanism in Java. In Kumpulan Makalah Seminar: Geologi dan Geotektonik Pulau Jawa, Sejak Akhir Mesozoik Hingga Kuarter. Jurusan Teknik Geologi, $U G M$, pp. 53-56. 
Sutanto. 2004. Perbukitan Jiwo Bayat merupakan warisan geologi Pra-Tersier dan Awal tersier di Jawa yang perlu dilestarikan. Warisan Geologi di Indonesia dan Malaysia.

Sutarto. 2016. Petrology, Geochemistry and Hydrotermal Fluid Evolution of The Randu Kuning Porphyry Cu-Au and Epithermal Au Deposit in Selogiri, Central Java (Dissertation). Universitas Gadjah Mada, Yogyakarta, p. 289.

Sutarto, S., Idrus, A., Harijoko, A., Setijadji, L. D., Meyer, F. M., Sindern, S., \& Putranto, S. (2016). Hydrothermal Alteration and Mineralization of the Randu Kuning Porphyry $\mathrm{Cu}-\mathrm{Au}$ and Intermediate Sulphidation Epithermal Au-Base Metals Deposits in Selogiri, Central Java, Indonesia. Journal of Applied Geology, 1(1), 1-18.

Sudarno, I. (1997). Kendali tektonik terhadap pembentukan struktur pada batuan Paleogen dan Neogen di Pegunungan Selatan, Daerah Istimewa Yogyakarta dan sekitarnya (Master Thesis) Magister Teknik, Institut Teknologi Bandung, Bandung, p. 167

Sumarso, T. I. (1975). Contribution to the Stratigraphy of the Jiwo Hills and Their Southern Surroundings (Central Java). Proceedings of 4th Annual Convention of Indonesia Petroleum Association, Jakarta, II, pp.19-26.

Sumosusastro, S. (1956). A Contribution to the Geology of the Eastern Djiwo Hills and The Southern Range in Central Java. University of Indonesia. Indonesian Journal for Natural Science, 112, 115-134.

Surono, Toha, B., dan Sudarno, I, 1992. Peta Geologi Lembar Surakarta-Giritontro, Jawa, Skala 1:100.000. Pusat Penelitian dan Pengembangan Geologi, Bandung.

Surono, S., Hartono, U., \& Permanadewi, S. (2006). Posisi stratigrafi dan petrogénesis intrusi Pendul, Perbukitan Jiwo, Bayat, Kabupaten Klaten, Jawa Tengah. Jurnal Geologi dan Sumberdaya Mineral, 16(5), 302-311.

Surono. 2008. Stratigrafi dan Sedimentasi Formasi Kebo dan Formasi Butak, di pegunungan Selatan, Jawa Bagian Selatan, Jurnal Geologi Indonesia, 3(4) 183-193

Surono, S. (2009). Litostratigrafi Pegunungan Selatan Bagian Timur Daerah Istimewa Yogyakarta dan Jawa Tengah. Jurnal Geologi dan Sumberdaya Mineral, 19(3), 209-221.

Suyoto. 1992. Stratigrafi Sikuen Cekungan Depan Busur Neogen Jawa Selatan Berdasarkan Data Di Daerah Pegunungan Selatan Yogyakarta (Tesis Master). Institut Teknologi Bandung, Bandung.

Choiriah, S. U., B Pratistho, B. P., RE Jati, R. E., \& Surono, S. (2006). Penilaian: Foraminifera Besar Pada Satuan Batugamping Formasi Gamping-Wungkal, di Sekarbolo, Perbukitan Jiwo, Bayat-Klaten. Jurnal Ilmи Kebumian Teknologi Mineral, 19(11),

van Bemmelen, R.W. 1949. The Geology of Indonesia Vol. IA. The Hague: Government Printing Ofiice, 732 p.

van Leeuwen, T.M., 1994. 25 Years of Mineral Exploration and Discovery in Indonesia. In: van Leeuwen, T.M., Hedenquist, J.W., James, I.P. and Dow, J.A.S. (Ed.), Indonesian Mineral Deposits-Discoveries of the Past 25 Years, Journal Geochemical Exploration, 50, 13-89.

Wijono, S. (1985). Stratigrafi Dan rekonstruksi Lingkungan Pengendapan Purba Endapan Karbonat Formasi Oyo, Di G. Tugu, Bayat, Kabupaten Klaten. Media Teknik, 7, 11-15 